\section{RAILROAD STGNALING.}

BY REGINALD GORDON, COLUMBIA COLLFGE, NFW YORK.

Tre chief object of signaling on railroads is to inform enginemen positively, at given points, whether they must stop or proceed, and the universal method of conveying this information is by a visible signal. Audible signals have been tried, but their use is rather limited. At the high speeds now usual on our railroads, an engineer ought to be able to interpret the meaning of a signal at some distance before he reaches it, so that if obliged to stop, he can bring his train under control and stop it, before reaching the point where actual danger exists, whether it be a train, an open switch, or some obstruction. The necessity of an easily distinguishable signal is thus obvious. In the early days of railroading, when trains were comparatively few and speeds were low, it was sufficient to have flagmen or watchmen, waving a flag by day, and a lantern at night. These men were of course governed by orders of the local superintendent or roadmaster. If a train stopped unexpectedly, or longer than usual, a brakeman was sent back with a flag or lantern to protect his train against a following one. Two great improvements were made in railroad operation when fixed siguals, on poles or posts alongside the track, were

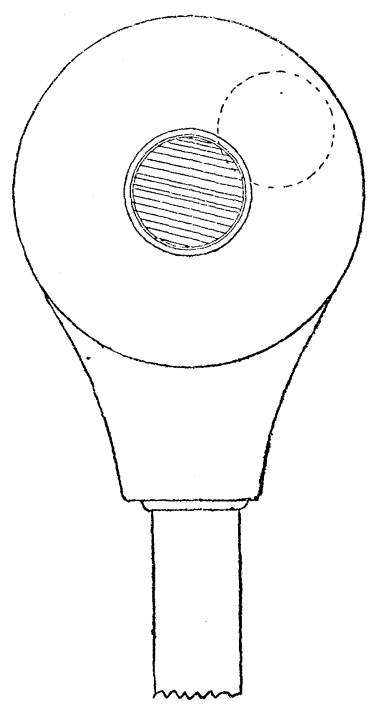

FIG. I.

adopted, and when the method of keeping trains apart, and protecting them, one against another, known as the "block signal" system was introduced. These fixed signals were moved by a combination of rods, wires and levers, worked by an operator situated at some distance and controlling, at the same time, several other signals in a similar manner.

Of all the different forms for signals that have been tried, the disc and the semaphore are the only ones in use now. The disc signal may give its indications for safety, either by turning through $90^{\circ}$, so as to show only its edge, or by moving bodily out of that part of the signal case which, when occupied, means "danger." Fig. 1 shows an electrically operated disc signal at "danger;" and the dotted lines show the "safety" position. The semaphore signal, fig. 2 , is more positive in its indication, because it is more easily discernible than a disc. The safety position of the semaphore is shown by the dotted lines in fig. 2. The blade or arm carries a frame, $F$, in which a red glass is fixed, so that at night, when the blade is raised to indicate danger, the lamp, $l$, fastened on the bracket, $b$, will show a red light. When lowered for safety, the lamp is uncovered, and, of course, shows white. The introduc- tion and recent rapid extension of block-signal systems of various kinds has led to the almost universal employment of semaphores, and even where an absolute block system is not maintained, train movements, either on the open road, or within yard limits, are controlled mainly by this form of signal. The necessity of keeping two trains apart by a space interval, rather than by a time-interval, has been demonstrated in a most forcible manner by the long list of rear-collisions on railroads relying solely on the rear brakemen to keep trains apart. In the former method the road is divided up into spaces or blocks, and no train is allowed to enter any block unless the last preceding train shall have passed beyond its limits. The limits of each space or block are marked by signals, usually semaphores, operated directly by a signalman, or else controlled by him through the intervention of compressed air and electricity. The safety of trains, then, rests mainly upon the faithfuiness of the signalmen, as well as the vigilance of the locomotive engineers.

Under the time-interval system, trains are not allowed to follow one another closer than after an interval of five, seven or ten minutes, according to the class of trains and their relative speed. With this system everything depends upon the faitbful and active performance of duty by the rear brakeman of a train. Some railroads, unable

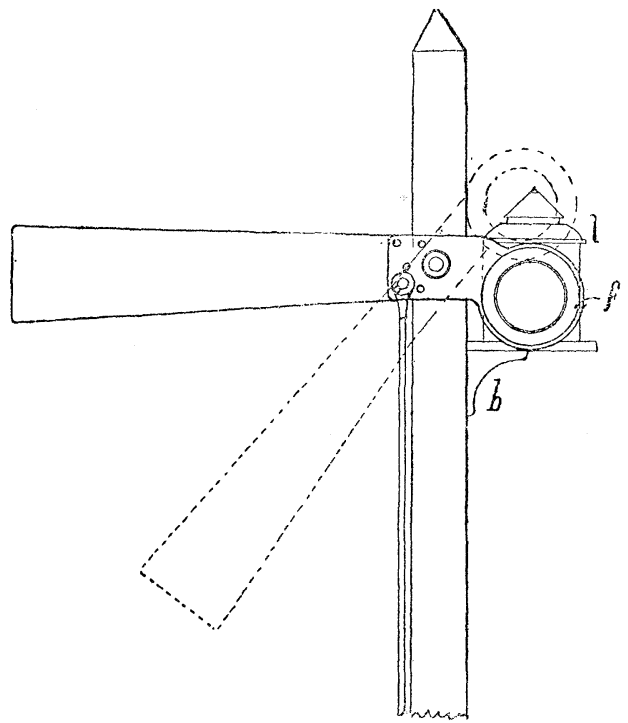

FIG. 2.

to incur the expense of installing and maintaining a firstclass block-signal system, have provided signals at every regular station, where the station agents, being in telegraphic communication with one another, can, if necessary, carry out a very fair "absolute" block system. Each station, then, marks the end of one section and the beginning of another. In times of heavy traffic, however, these blocks between stations are too long; that is, trains are kept too far apart, and compelled to wait so long at stations that the road could not be kept clear, and the service would become demoralized if this method were strictly adhered to. For these reasons, and under the circumstances cited, it is quite usual to allow trains to follow one another after an interval of time, determined in each case to suit the circumstances, and the practice thereby becomes "permissive," as opposed to "absolute" blocking. This method of operating is in use at present on many roads, and, though it no doubt prevents many collisions, is vastly inferior to an absolute, interlocking system of block signals.

Railroads with very heavy traffic, and traversing thickly settled regions, have lately found it necessary and expedient to equip their lines with this latter system, and it 
is a question of only a few years before all our great trunk lines, or, in fact, all lines running trains at high speed will be thus protected. The earlier forms of block systems comprised a semaphore for each track, controlled from a cabin or tower at the entrance to each block or section. Telegraphic communication was established between these towers, and the movement of trains thus pretty well controlled, of course always assuming proper vigilance and devotion to duty on the part of the tower men and engineers. Nevertheless, accidents have happened by reason of a signalman forgetting that a train has lately passed his tower, and allowing another to fol-

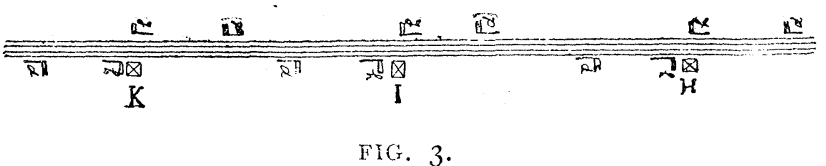

low it, without any information from the tower ahead. In the latest systems brought into use, the danger of such carelessness is largely, if not entirely, overcome, by interlocking the signal levers in two successive towers. By a combination of mechanical and electrical devices, each lever that moves a signal is locked in position by the man in the tower at the farther end of the block section, and can be unlocked only with the latter's consent and coöperation. For example, in fig. 3, a signalman at $H$ cannot lower his signal to "safety," in order to admit a train to the block ahead, without asking the operator at the next tower, $I$, to unlock his ( $H$ 's) lever. The man at $I$ will not do this unless he knows that the block or section $H-I$ is clear. A train having passed $I$, going towards $K$, and protected by a danger signal at $I$, the signalman there, on request of $H$, will unlock the latter's signal

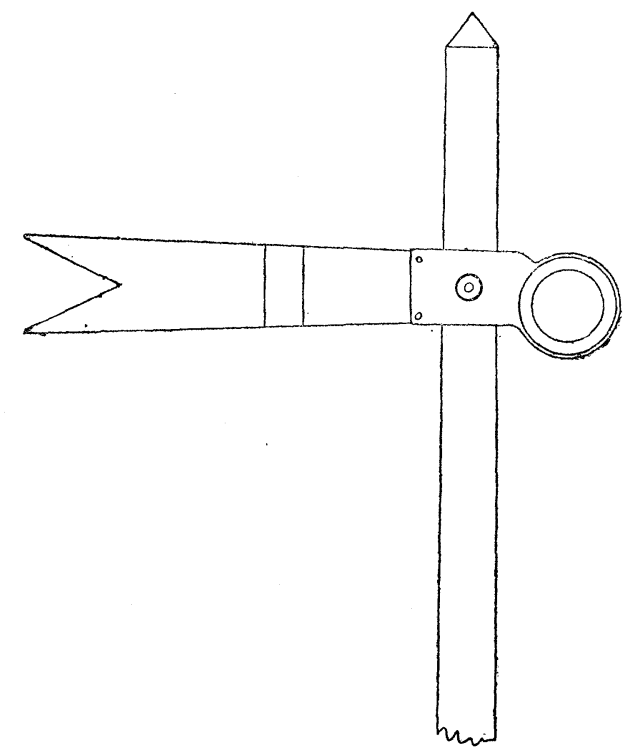

FIG. 4.

lever, so that he can lower his semaphore to safety, and admit a train to block $H-I$. It is usual, also, to have each signal in duplicate; that is, a semaphore placed from 1,200 to 1,600 feet in advance of the one at which an engineer must stop, if it stand at danger. The latter is called the "home" signal; the former, the "distant" signal. Home signals are almost invariably painted red, and of the form shown in fig. 1. At night they display a red light when the blade is raised to danger position. Distant signals are made of the "fish-tail" form, as shown in fig. 4, and painted green or, rarely, yellow, displaying a green light at night when raised to indicate "caution." A distant signal is for the purpose of informing an engineer whether he will find the home signal at danger or not. In moving the blades to indicate danger, the distant is first raised, then the home signal. In lowering them, however, the reverse order is used. If an engineer finds the distant signal lowered for him, he can go on confidently without slackening speed, knowing that he has a clear block ahead. If, however, it is against him, he then has time to bring the train under control and come to a dead stop on reaching the home signal, which, if at danger still, he must under no circumstances pass. In the Fourth Avenue tunnel, New Fork City, the signals are arranged so that the act of moving a signal to danger, places a torpedo on the rail over which the train must pass, and in addition to this, a gong is set loudly ringing if an engineer, neglecting the ordinary signal, runs beyoud a certain point. Setting the signal to safety again removes the torpedo and throws off the gong mechanism. These extra safeguards have been found to be absolutely necessary in this place, where the traffic is so dense and the conditions of working are so trying.

\section{ALTTIUDE IN SPITE OF HUMDDTIY AS A CURE OF' BERI-BERI**}

\author{
BY ALBERT S. ASHMEAD, M. D., NEW YORK.
}

The Hakoné Mountain resorts, 836 metres above sealevel, Karuizawa, the new foreign resort, the religious stations (ten) disposed on each of the four roads up the sacred Fuji Mountain, and the Ikao Mountain and hot springs resort at Nikko, are the main beri-beri resorts of Japan. All these are in the neighborhood of volcanic centres. Karuizawa, at the head of the Usui Pass, is 3,000 feet above sea-level. Its mean temperature is $8^{\circ}$ lower than that of Tokio, in the principal Kakké month, August; and there is a mean oscillation of $20^{\circ} \mathrm{F}$. in the temperature of the day, as compared with the night. While at Tokio the variation is only $14^{\circ}$. It is this coolness of the nights, in all the mountain resorts of Japan, which makes the heat of the day tolerable. The August humidity, in all the mountains of Japan, although they have three times the rainfall of Tokio, is practically the same as in the latter city.

Yamanaka, another resort in the Hakoné Mountains, is higher even than Karuizawa, the same conditions as above.

Fuji, the peerless mountain of Japan, is 12,238 feet high. Its slopes are cultivated to an elevation of 2,000 feet. It can only be visited in the Kakké season, July and August. At other seasons, it is too cold. The highest temperature that has ever been recorded in August, on the summit of Fuji, was $70.5^{\circ}$, and the lowest $31.1^{\circ}$. The mean daily range of temperature is a little higher, $20.9^{\circ}$, than at Karuizawa; that is the variation between day and night. There are at the top of the mountain thirty-six inches of rainfall, and three-fourths of the whole quantity belong to the three or four days of the first storm of the month. The influence of $F u j i$ in encouraging precipitation, is shown also at Karuizawa, the latest beri-beri resort, and in the other resorts. ${ }^{\mathrm{I}}$

The comparison between the three, top of Fuji, Yamanaka on the Hakoné Mountains, and Karuizawa, gives the following figures:

Bar. Range. Temp. Range. Vap. Hum. fail. Rainy Top of Fuji......4 490.7 I3.I 7.7 II.6 $5.5 \quad 71.2 \quad 888.1$ I 8

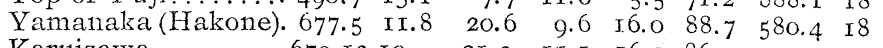
Karuizawa.......679.13 1o. 21.3 Ix.I 16.0 86. 212.0 I7 *Communicated to the Sei-I-Kwai, or Society for the Advancement of Medical Science in Japan.

Ashino-yu is at Ubago, near the base of Fuji. Hakone Lake is separated from Fuji by a ridge. Yamanaka Lake is seen from the top of second highest volcanic peais iu Julut! (Shinano.) 